\title{
Fluorescence Spans the Globe
}

\author{
David J S Birch ${ }^{1}$, Yves Mely ${ }^{2}$ and Otto Wolfbeis ${ }^{3}$ \\ ${ }^{1}$ The Photophysics Research Group, University of Strathclyde, Department of Physics, SUPA, John \\ Anderson Building, 107 Rottenrow, Glasgow, G4 ONG, United Kingdom \\ ${ }^{2}$ Laboratoire de Bioimagerie et Pathologies,UMR7021 CNRS, Faculté de Pharmacie, Université de \\ Strasbourg, Cedex, 67401 Illkirch, France \\ ${ }^{3}$ Institute of Analytical Chemistry, Chemo- and Biosensors, University of Regensburg, 93040 \\ Regensburg, Germany \\ E-mail: djs.birch@strath.ac.uk
}

Dear Authors, Reviewers and Editors

2018 proved to be another exciting and productive year for Methods and Applications in Fluorescence (MAF). Regular article submissions continued to grow, increasing by $30 \%$ on 2017 . At the same time the quality for the journal was preserved by its acceptance rate of 1 in 3 submissions and this should lead to further increase in impact factor in the years ahead. Indeed the quality is evident in 2018 regular articles, several already having 3 or 4 citations.

During 2018 we were very pleased to launch a tutorial series in MAF. Concentrating on the didactical approach that is so important for research training the first tutorial published was Inclusion of fluorophores in cyclodextrins: a closer look at the fluorometric determination of association constants by linear and nonlinear fitting procedures by Rudi Hutterer ${ }^{1}$. We very much welcome unsolicited tutorials so please keep this in mind when dusting off your lecture notes to start the next semester's lectures on fluorescence.

Although the 2017 impact factor dropped a little to 2.17 the journal is still the leader in the field. Our topical reviews in particular seem to be very well cited and making a key contribution to the field. Of special note was the review in 2018 An introduction to optical super-resolution microscopy for the adventurous biologist by J Vangindertael, R Camacho, W Sempels, H Mizuno, P Dedecker and K P F Janssen $^{2}$ which received over 6500 downloads in the first 6 months! Also worthy of special mention is Fluorescent J-aggregates of cyanine dyes: basic research and applications review by J L Bricks, Y L Slominskii, I D Panas and A P Demchenko ${ }^{3}$ with 11 citations in the same year of publication.

\footnotetext{
${ }^{1}$ Inclusion of fluorophores in cyclodextrins: a closer look at the fluorometric determination of association constants by linear and nonlinear fitting procedures Rudi Hutterer 2018 Methods Appl. Fluoresc. 6013001

${ }^{2}$ An introduction to optical super-resolution microscopy for the adventurous biologist J Vangindertael et al 2018 Methods Appl. Fluoresc. 6022003

${ }^{3}$ Fluorescent J-aggregates of cyanine dyes: basic research and applications review

J L Bricks et al 2018 Methods Appl. Fluoresc. 6012001
} 
Do keep an eye out in 2019 for topical reviews on Sensing with Photoluminescent Semiconductor Quantum Dots by Margaret Chern and Allison Dennis, Chirality in fluorescence and energy transfer by David Andrews and Photons in - numbers out: Perspectives in quantitative fluorescence microscopy for in situ protein counting by Dirk-Peter Herten.

In Special Issues we had one on Upconversion Methods, Applications and Materials edited by Julia Pérez Prieto and Hans-Heiner Gorris ${ }^{4}$ and papers from the 2017 Bruges MAF meeting edited by Yves Mély and Johan Hofkens ${ }^{5}$. The MAF conference will be held in the USA for the first time in 2019. Chaired by Yitzhak Tor the $16^{\text {th }}$ meeting (http://maf2019.ucsd.edu/) in the series will be held in La Jolla California between August 20-24 2019 and the Proceedings from the conference will again be published in the MAF Journal. From 2019 the MAF conference will be an annual event, alternating between Europe and North America, and this serves to highlight the growing interest in fluorescence across the globe.

We very much look forward to enjoying fluorescence with you in La Jolla in 2019 and reading the latest developments in fluorescence in the MAF journal. Until then we wish to express our sincere gratitude to all the authors, reviewers and editorial board who have supported the journal throughout the year, and end by wishing the whole fluorescence community a happy and successful New Year ahead.

\footnotetext{
${ }^{4}$ http://iopscience.iop.org/journal/2050-6120/page/Special-issue-on-Upconversion-Methods-Applicationsand-Materials

${ }^{5}$ http://iopscience.iop.org/journal/2050-6120/page/maf-2017
} 